\title{
Flow and heat transfer in a rectangular converging (diverging) channel: new formulation
}

\author{
Roohi Laila', Dil Nawaz Khan Marwat ${ }^{1}$ and Azhar Ali ${ }^{2 *}$
}

\author{
${ }^{*}$ Correspondence: \\ azhar_ali017@yahoo.com \\ ${ }^{2}$ Electrical Department \\ Sarhad University of Science \\ and Information Technology \\ Peshawar, Khyber \\ Pakhtunkhwa, Pakistan \\ Full list of author information \\ is available at the end of the \\ article
}

\begin{abstract}
In this paper, a model problem of viscous flow and heat transfer in a rectangular converging (diverging) channel has been investigated. The governing equations are presented in Cartesian Coordinates and consequently they are simplified and solved with perturbation and numerical methods. Initially, symmetrical solutions of the boundary value problem are found for the upper half of the channel. Later on, these solutions are extended to the lower half and then to the whole channel. The numerical and perturbation solutions are compared and exactly matched with each other for a small value of the parameters involved in the problem. It is also confirmed that the solutions for the converging/diverging channel are independent of the sign of $m$ (the slope). Moreover, the skin friction coefficient and heat transfer at the upper wall are calculated and graphed against the existing parameters in different figures. It is observed that the heat transfer at walls is decreased (increased) with increasing $c_{1}$ (thermal controlling parameter) for diverging (converging). It is also decreased against $\operatorname{Pr}$ (Prandtle number). For $c_{1}=0$, the temperature profiles may be exactly determined from the governing equations and the rate of heat transfer at the upper wall is $\theta^{\prime}(1)=\frac{m}{\left(1+m^{2}\right) \tan ^{-1} m}$. It is confirmed that the skin friction coefficient behaves linearly against $\mathrm{Re}^{*}$ (modified Reynolds number) and it is increased with increasing of Re* (changed from negative to positive). Moreover, it is increased asymptotically against $m$ and converges to a constant value i.e. zero.
\end{abstract}

Keywords: Flow and heat transfer, Channel of rectangular inclined plan, Walls Introduction

\section{Introduction}

Unwanted heat is produce during the electrical and mechanical processes, whereas, its control and minimization is necessary for the durability of all such devices. Heat transport is important in many devices of practical uses; therefore, heat transfer in multiple engineering disciplines is of great interest. The practical applications of heat flow in solar collectors, heaters devices it is the first priority of engineers and physicists to develop accurate models of heat transfer with proper physically and mathematically tenable conditions. Therefore, this field is thoroughly investigated in many research papers [1-4].

(c) The Author(s), 2021. Open Access This article is licensed under a Creative Commons Attribution 4.0 International License, which permits use, sharing, adaptation, distribution and reproduction in any medium or format, as long as you give appropriate credit to the original author(s) and the source, provide a link to the Creative Commons licence, and indicate if changes were made. The images or other third party material in this article are included in the article's Creative Commons licence, unless indicated otherwise in a credit line to the material. If material is not included in the article's Creative Commons licence and your intended use is not permitted by statutory regulation or exceeds the permitted use, you will need to obtain permission directly from the copyright holder. To view a copy of this licence, visit http:// creativecommons.org/licenses/by/4.0/. 
Converging and diverging channels have many applications in industry especially to increase the efficiency of devices in order to increase/decrease heat transfer. The design of such channels is extensively used in the physical problems and it is known fact that the heat transfer increase with the increase of surface area per volume. The boundary layers are merged with each other and specially mixing zones are formed in the flow region to enhance and sensitize the heat transfer coefficient. Researchers produce a lot of new research work on the basis of physical models of practical interest and establish valid results for simulated problems. Mendes and Sparrow [5] analyzed the diffusion of heat in flow inside a converging and diverging tubes they specified the entrance and developing regions. Note that, the heat transfer coefficient, the pressure rise (drop) and friction factor are grown effectively in multiple taper angles. Garg and Maji [6] found the proper numerical configuration for the flow inside the converging and diverging channel, however, it is a most suitable method for calculating the heat transfer in such cases. Amon and Mikic [7] explored numerical solutions for heat transfer in interrupted channels and they demonstrated the behavior of non-steady state self-sustained oscillating flow. Fluid flow and heat transport inside a channel of wavy walls is examined in Wang and Vanka [8] and they concluded that heat flow is changed significantly with the small changes in pressure drop. The experimented investigation of turbulent flow in a rectangular channel containing the built-in wing type vortex generators are found in [14], and they claimed that heat transfer caused vortices in this flow. Dejond and Jacobi [9] evaluated mass transfer at interrupted plate arrays with the help of experiment and they conclude that the mass transfer is much higher than the expected values. The converging and diverging channel are widely manipulated as finned surfaces in Caliskan and Baskaya [10] and Kotcioglu et al. [11]. Heat transfer in converging and diverging channels is first investigated theoretically and experimentally in Yilmaz [12]. They proved that flow (which is perpendicular to steam direction), increases heat transfer in a channel of parallel plates. They provided experimental data, which shows that heat transfer enhances with improving of Reynolds number. The literature is rich enough about the utilization of periodic boundary condition in fluid flow and heat transfer analysis [12-14]. The models of converging (diverging) channels are also provide a background for automobile radiators, PV collectors, gas-gas heat exchangers, liquid-liquid plate heat exchangers, etc. The numerical study of communicating converging (diverging) channel is given in Yilmaz and Erdinç [12].

Two-dimensional radial flow in an infinite converging (diverging) channel produced by linear source (sink) is studied in $[15,16]$. More accurate results of such flow are provided see Rosenhead [17], Millsaps and Pohlhausen [18]. Researchers found more properties of these flow models while analyzing the Jeffery-Hammel model and they provided asymptotic solution in the form of series. Moreover, approximate analytical solutions for the flow inside the symmetrical channels are evaluated in Fraenkel [19] and he assumed that the channel is composed of slightly curved walls. Later on, Drazin [20] investigated the instability of flows maintained inside the converging (diverging) channel. He found that the mass flux is increased steadily along the channel. The temporal instability of Jeffery-Hammel flow is also analyzed in Hamadchi et al. [21]. Details of both experimental and theoretical studies of such model can be found in Dennis et al. [22]. They assumed flow between solid boundaries in polar coordinates $(r, \theta)$ and the fluid motion 
is maintained via a source or sink at origin where the walls of a channel are situated at $\theta= \pm a$. The past models are strictly presented in polar coordinates and concerned with purely radial flows. The idea of radial flows given in [23] is commonly propagated in literature, whereas, they formulate and present well-known converging/diverging flow problems. The investigation of flow in converging/diverging channel/tube is further elaborated, however, consequences of other physical effects are studied on flow characteristic in Rehman et al. [24]. Ramesh and Devakar [25] used different methods to explore flow behavior in such channels. A common approach is used in all these research papers, however, it is strictly based on utilization of similarity transformation, which converts the equation of motion into ODE's. Viscous flow in a converging/diverging channel is studied in Turkyilmazoglu [26], moreover, he analyzed Jeffery-Hammel flows for stretching (shrinking) walls of the channel. Heat transfer inside converging/diverging channel of stretching (shrinking) walls is examined in the presence of viscous dissipation effects. The problem of fluid flow and heat transfer in converging channel is studied by Turkyilmazoglu [27]. He gives exact (closed form) multiple solutions to the momentum and energy equation associated with momentum and thermal slip boundary conditions. The exact multiple solutions and numerical results of the modeled problem are exactly matched for a small value of the parameters. The flow problem is strictly depend upon the appropriate coordinate system and geometry of the problem, so the right choice for choosing the proper coordinate system decides on the bases of flow problem see [28]. Many research articles are available on a purely radial flow in a converging/diverging channel for both Newtonian and non- Newtonian fluids. Makinde [30] presented a compact model of channel flow and he found the numerical and perturbation solutions of simulated problem, however, he investigated an incompressible viscous nanofluid in four different types of channels (divergent, convergent, locally constricted and wavy). Note he solved a system of ODE's with the perturbation series method, furthermore, he found accurate results for heat and mass transfer with special cases in the channels. Makinde [31] also examined the steady flow of incompressible viscous fluid inside a diverging symmetrical channel, furthermore, he presented the Taylor series solution to the modeled problem and all the field variables are evaluated and computed accurately using this method.

The previous problems of converging and diverging flow are simulated in polar coordinates system, whereas, we demonstrate the fluid flow and heat transfer problems in converging (diverging) channels of rectangular plan walls. The investigations of this paper have not been discussed in the open literature and a new problem of rectangular channels is simulated, whereas, we solved the momentum and energy equations for a converging (diverging) channel of rectangular walls. A set of appropriate transformation is formed for the stream function and temperature variables which reduces the Navier-Stokes and energy equations into ODE's and the final system of equations is solved with the regular perturbation method. A numerical method is also employed for confirmation and validation of the approximate analytical solutions. The numerical technique used here is the finite difference method, which is based on polynomial collocation with four Lobatto points. It is observed that the velocity and temperature profiles are charged significantly with the slope $m$ of the upper wall and characteristic number Re. The skin friction coefficient and heat transfer from the 
upper wall are graphed against different parameters. Further, the classical work of Millsaps and Pohlhausen [18] is also recovered from the result of the current model, whereas, the two solutions are exactly matched with each other.

\section{Formulation of the problem}

Consider a rectangular converging/diverging channel of heated inclined plane walls with variable gap $h(x)$ between them. The upper (lower) wall has slope $m(-m)$. The gap between walls is $2 h(x)$ and the constant gap is $a_{0}$ when $x=0$. A line is drawn at the center of the channel which is equidistance from the upper and lower walls and representing the $x$-axis whereas the $y$-axis is normal to it. Note that the walls of a channel are equally heated and have a variable temperature. A steady flow of an incompressible viscous fluid is maintained in a two dimensional channel of inclined plane walls. The velocity vector has decomposed into two orthogonal components i.e. the axial velocity $(u)$ in $x$-direction and the normal velocity $(v)$ in the $y$-direction. Here, we considered a problem of converging (diverging) flow in a rectangular channel whose upper (lower) wall is situated at $y=m x+a_{0}\left(y=-m x-a_{0}\right)$ where $m$ is the slope of upper (lower) wall and $2 a_{0}$ is entrance (for diverging flow)/exist (for converging flow) channel's height. The upper wall of the channel has variable temperature $T_{w}(x)=T_{0}+T_{1}\left(a_{0}+m x\right)^{c_{1}}$ and the fluid at the center has uniform temperature $T_{0}$. The parameter $m=0$ is representing the flow and heat transfer between parallel walls and for that choice of $m$, the model problem is exactly reduced to the well-known Poiseuille model of one dimensional flow and heat transfer between parallel plates. Here we assumed similar flows and the velocity vector has normal and axial components whereas the classical Jeffery-Hammel model is equipped with only a radial component of velocity. The fluid attached to the plates has the velocity of solid sheet and would behave like walls. The axial velocity $u(x ; y)$ is maximum i.e. $U(x)$ at the mid of channel or at $y=0$. The normal velocity component and vorticity function will be zero at mid $(y=0)$ of channel due to symmetry conditions. Moreover, the center line as a reference stream line. The following equations are used for governing the incompressible viscous flow and heat transfer in the converging/diverging channel (Fig. 1).

Continuity equation:

$$
\frac{\partial u}{\partial x}+\frac{\partial v}{\partial y}=0
$$

The component of Navier-Stokes equations:

$$
\begin{aligned}
& u \frac{\partial u}{\partial x}+v \frac{\partial u}{\partial y}=-\frac{1}{\rho} \frac{\partial p}{\partial x}+v\left(\frac{\partial^{2} u}{\partial x^{2}}+\frac{\partial^{2} u}{\partial y^{2}}\right) \\
& u \frac{\partial v}{\partial x}+v \frac{\partial v}{\partial y}=-\frac{1}{\rho} \frac{\partial p}{\partial x}+v\left(\frac{\partial^{2} v}{\partial x^{2}}+\frac{\partial^{2} v}{\partial y^{2}}\right)
\end{aligned}
$$

The energy equation: 


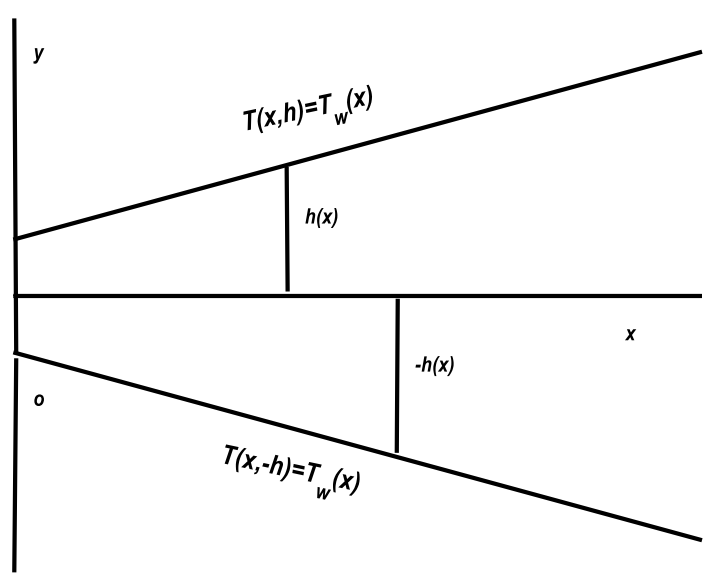

Fig. 1 The converging (diverging) channel and geometry of the problem

$$
\rho c_{\rho}\left(u \frac{\partial T}{\partial x}+v \frac{\partial T}{\partial y}\right)=\kappa\left(\frac{\partial^{2} T}{\partial x^{2}}+\frac{\partial^{2} T}{\partial y^{2}}\right)
$$

The boundary conditions for the flow problem are:

$$
\begin{aligned}
& u(x, y)=U(x), \quad(x, y)=0, \quad \psi(x, y)=0, \quad T(x, y)=T_{0} ; \quad y=0 \\
& u(x, y)=0 \quad \text { and } \quad T(x, y)=T_{w}(x) ; \quad y=h(x) \\
& \xi=\frac{\partial v}{\partial x}-\frac{\partial u}{\partial y}
\end{aligned}
$$

where in Eq. (7) the vorticity $(\xi)$ is defined and $v, \rho, p$ are kinematic viscosity, density and pressure, respectively. In view of the stream function formulation the velocity components are

$$
u=\frac{\partial \psi}{\partial y}, \quad v=\frac{\partial \psi}{\partial x}
$$

Now defining the stream function $(\psi)$ in term of such that

$$
\begin{gathered}
\psi=h(x) U(x) f(\eta), \quad T=\Delta T \theta(\eta)+T_{0} \quad \text { where } \quad \eta=\frac{y}{h(x)} \\
\Delta T=T_{w}-T_{0}=T_{1}\left(m x+a_{1}\right)^{c_{1}}, \quad h(x)=a_{0}+m x, \quad U(x)=\frac{U_{0} a_{0}}{a_{0}+m x}
\end{gathered}
$$

The vorticity equations is formed by eliminating pressure term between Eqs. (2) and (3).

$$
u \frac{\partial \xi}{\partial x}+v \frac{\partial \xi}{\partial y}=v\left(\frac{\partial^{2} \xi}{\partial x^{2}}+\frac{\partial^{2} \xi}{\partial y^{2}}\right)
$$

where the vorticity function $\xi$ is defined as: 


$$
\xi=\frac{\partial v}{\partial x}-\frac{\partial u}{\partial y}
$$

The transformations in Eqs. (7) and (9) are used and converted the energy Eq. (4) and vorticity Eq. (10) into the following ODE's:

$$
\begin{aligned}
& \left(1+m^{2} \eta^{2}\right)^{2} f^{i v}+12 m^{2} \eta\left(1+m^{2} \eta^{2}\right) f^{\prime \prime \prime} \\
& +12 m^{2}\left(1+3 m^{2} \eta^{2}\right) f^{\prime \prime}+2 m \operatorname{Re}\left(1+m^{2} \eta^{2}\right) f^{\prime} f^{\prime \prime} \\
& +4 m^{3} \operatorname{Re} \eta\left(f^{\prime}\right)^{2}+24 m^{4} \eta f^{\prime}=0 \\
& c_{1} m^{2}\left(1-c_{1}\right) \theta+c_{1} m \operatorname{Pr} \operatorname{Re} f^{\prime} \theta-2 m^{2} \eta\left(1-c_{1}\right) \theta^{\prime}-\left(1+m^{2} \eta^{2}\right)^{2} \theta^{\prime \prime}=0 \\
& f(0)=0, \quad f^{\prime \prime}(0)=0, \quad f^{\prime}(0)=1, \quad f^{\prime}(1)=0, \quad \theta(0)=0, \quad \theta(1)=1
\end{aligned}
$$

where $\operatorname{Re}=\frac{a_{0} U_{0}}{v}, \operatorname{Pr}=\frac{v}{\alpha}$ are used for Prandtl number and Reynolds number, respectively.

\section{Methods}

\section{Perturbation solution}

Perturbation solution of the modeled problem is given below. The perturbation solution is obtained for a small value of $m$, where $m$ is representing the slope of the upper wall of the channel. The unknown quantities $f$ and $\theta$ are expanded in terms of $m$ as:

$$
\begin{aligned}
& f=f_{0}+m f_{1}+m^{2} f_{2}+m^{3} f_{3}+O\left(m^{4}\right) \\
& \theta=\theta_{0}+m \theta_{1}+m^{2} \theta_{2}+m^{3} \theta_{3}+O\left(m^{4}\right)
\end{aligned}
$$

By substituting the expressions for $f$ and $\theta$ from Eqs. (15)-(16) into (12)-(14) and equate like powers of $m$ on both sides of them, we obtained the zeroth, first, second and third order systems. The zero, first, second and third order systems are solved for $f_{0}, \theta_{0}, f_{1}, \theta_{1}, f_{2}, \theta_{2}, f_{3}, \theta_{3}$ and we get the following solution.

$$
\begin{aligned}
& f_{0}=\frac{1}{3}\left(3 \eta-\eta^{3}\right) \\
& \theta_{0}=\eta \\
& f_{1}=\frac{1}{630}\left(-28 \operatorname{Re} \eta^{3}+21 \operatorname{Re} \eta^{5}-3 \operatorname{Re} \eta^{7}\right) \\
& \theta_{1}=\frac{-1}{60}\left(c_{1} \operatorname{Pr} \operatorname{Re} \eta\left(7-10 \eta^{2}+3 \eta^{4}\right)\right)
\end{aligned}
$$




$$
\begin{aligned}
f_{2}= & -\left(\frac{2}{3} \operatorname{Re}^{2} \frac{163}{56700}\right) \eta^{3}+\left(\frac{2}{5} \operatorname{Re}^{2} \frac{1}{225}\right) \eta^{5} \\
& -\frac{1}{350} \operatorname{Re}^{2} \eta^{7}+\frac{1}{1260} \operatorname{Re}^{2} \eta^{9}-\frac{1}{14850} \operatorname{Re}^{2} \eta^{11} \\
\theta_{2}= & \frac{1}{151200}\left(\eta ( - 1 + \eta ^ { 2 } ) \left(-5040+c_{1}\left(75600-2 \operatorname{Pr} \operatorname{Re}^{2}\left(239+239 \eta^{2}-265 \eta^{4}+35 \eta^{6}\right)\right.\right.\right. \\
+ & \left.\left.\left.3 c_{1}\left(-8400+\operatorname{Pr}^{2} \operatorname{Re}^{2}\left(-491+489 \eta^{2}-225 \eta^{4}+35 \eta^{6}\right)\right)\right)\right)\right) \\
f_{3}= & \operatorname{Re}^{3}\left(-\frac{1}{63}+\frac{13}{150} \eta^{2}-\frac{1}{14} \eta^{4}+\frac{4}{315} \eta^{6}\right)+\frac{\operatorname{Re}^{3} \eta^{3}}{8100}\left(\frac{163}{70} \eta^{2}-\frac{2179}{3003}-\frac{751}{245} \eta^{4}\right. \\
& \left.+\frac{29}{14} \eta^{6}-\frac{573}{770} \eta^{8}+\frac{127}{1001} \eta^{10}-\frac{1}{130} \eta^{12}\right) \\
\theta_{3}= & \frac{1}{1297296000} c_{1} \operatorname{Pr} \operatorname{Re} \eta\left(-1+\eta^{2}\right)\left(2 c _ { 1 } \left(5405400\left(7-10 \eta^{2}+3 \eta^{4}\right)\right.\right. \\
+ & \left.\left.\operatorname{Pr}^{2} \operatorname{Re}^{2}\left(-339263+250 \eta^{2}+404480 \eta^{4}-341980 \eta^{6}+99175 \eta^{8}-8855 \eta^{10}\right)\right)\right) \\
+ & \left(-128700\left(-60-179 \eta^{2}+115 \eta^{4}\right)-\operatorname{Re}^{2}\left(19412+19412 \eta^{2}-50515 \eta^{4}\right.\right. \\
+ & \left.\left.35285 \eta^{6}-9760 \eta^{8}+770 \eta^{10}\right)\right)+c_{1}^{2}\left(-514800\left(69-50 \eta^{2}+13 \eta^{4}\right)\right. \\
+ & \left.\operatorname{Pr}^{2} \operatorname{Re}^{2}\left(-966443+113994 \eta^{2}-753230 \eta^{4}+284950 \eta^{6}-63255 \eta^{8}+5775 \eta^{10}\right)\right)
\end{aligned}
$$

The final perturbation solution is obtained when we substitute the zeroth, first, second and third order solutions from Eqs. (17)-(24) into (15)-(16). The unknown pressure is calculated from Eqs. (2)-(3). The transformation from Eqs. (8)-(9) are substituted into Eqs. (2)-(3) and we get the following ODE's for the pressure term:

$$
\begin{aligned}
& m \eta g^{\prime}+2 m g=-2 m^{2} f^{\prime}-m \operatorname{Re} f^{\prime 2}-4 m^{2} \eta f^{\prime \prime}-\left(1+m^{2} \eta^{2}\right) f^{\prime \prime \prime} \\
& g^{\prime}=6 m^{3} \eta f^{\prime}+m^{2} \eta \operatorname{Re} f^{\prime 2}+\left(2 m+6 m^{3} \eta^{2}\right) f^{\prime \prime}+\left(m \eta+m^{3} \eta^{3}\right) f^{\prime \prime \prime}
\end{aligned}
$$

Substituting values of $g^{\prime}$ from Eqs. (26) into (25), we get the following expression for $g$ (the representative of pressure).

$$
g=-\left(3 m^{3} \eta^{2}+m\right) f^{\prime}-\left(\frac{\left(m^{2} \eta^{2}+1\right) \operatorname{Re}}{2}\right) f^{\prime 2}-3 m \eta\left(1+m^{2} \eta^{2}\right) f^{\prime \prime}-\left(m \eta^{2}+\frac{m^{3} \eta^{4}}{2}+\frac{1}{2 m}\right) f^{\prime \prime \prime}
$$

\section{Numerical solution}

The numerical solution of Eqs. (12)-(14) is obtained with the help of finite difference method, which is based on polynomial collocation with four Lobatto points. The scheme is developed for solution of boundary value problem, whereas, produced Cebeci and Keller is produced it and the code is established with the name $b v p 4 c$ in MATLAB. The 
governing equations (continuity, momentum and energy) are transformed into a simplest system of boundary values ODE's with the help of similarity transformation discussed in Khan Marwat et al. [29]. The problem is formulated for the upper half channel and characterized by slop $m$ of the upper wall of the channel, the Reynold's number, Prandtl number, and a temperature controlling parameter $c_{1}$. The following procedure is established to distinguish between different physical situations. Note that the mathematical model is presented for upper half of the channel. The modeled problem is classified into the following case on the bases of parameters and their numerical values:

- $m>0$ and $\operatorname{Re}>0(\operatorname{Re}<0)$ corresponds to the diverging (converging) flow in the upper half of the channel.

\section{Results and discussion}

Note that the modeled equations are valid in the upper channel subject to above-established criteria. The perturbation solutions are simultaneously valid for upper half of the channel or the whole channel. Moreover, the profiles in Fig. 2 are symmetrical about the center line for different values of $\operatorname{Re}^{*}$ and $m=0$. The profiles are obtained from the numerical solution of Eq. (12) for $m=0$, $\operatorname{Re}^{*}=-100,-20,-10,-5,1,5,10$, 20. The equations are solved in upper channel. The solutions of Eqs. (12)-(14) are symmetrical about the mid line of the channel for both converging and diverging flows. When $m * \operatorname{Re}$ is replaced by $\mathrm{Re}^{*}$ in Eq. (12) then the profiles are only symmetrical for $m=0$. For $m=$ $0, \operatorname{Re}=0$, the model presents flow and heat transfer between parallel plates and ensures the classical observation of Poiseuille. It is observed from this figure that the parabolic profiles are extending towards wall with the increasing of Re*. However, the parabola shrinks towards the center for increasing the negative value of $\mathrm{Re}^{*}$. Note that the parabolae in all profiles of this figure have the same peaks. Nonetheless the profiles are plotted for $m=0$ and different $\mathrm{Re}^{*}$ and show significant changes in the patterns of the profiles. Hence, it is likely that not all profiles at large $\operatorname{Re}^{*}>0$ are shown over here. In Fig. 2 the stream wise velocities are graphed for $m=0$, moderate, and high Reynolds number ( $\mathrm{Re}^{*}$ $>0$ and $\mathrm{Re}^{*}<0$ ). The velocity profiles are highly sensitive to $\mathrm{Re}^{* *}$ for this set of parameters

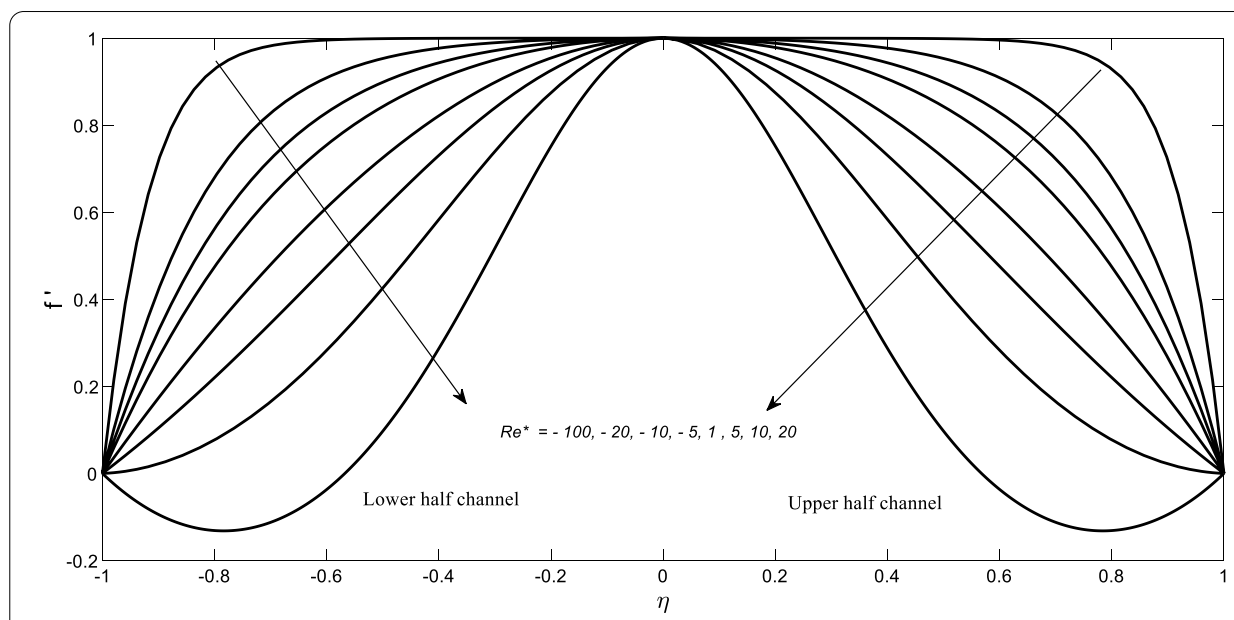

Fig. $2 f^{\prime}$ is graphed against $\eta$ for $m=0$ where $\operatorname{Re}^{*}=m \operatorname{Re}$ 


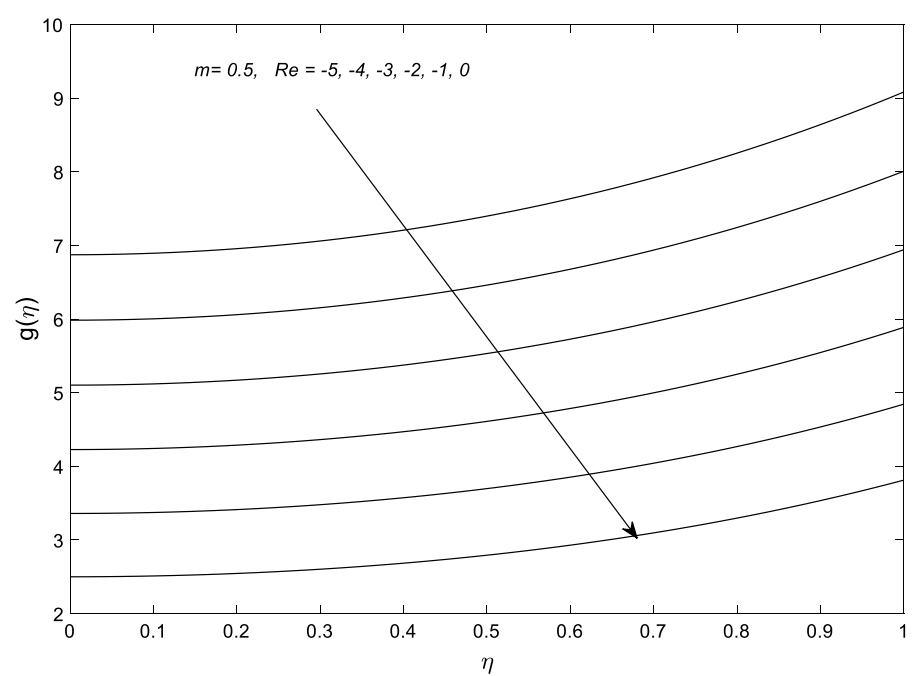

Fig. $3 g$ is graphed against $\eta$ for different $\operatorname{Re}^{*}$ where $\mathrm{Re}^{*}=m \operatorname{Re}$

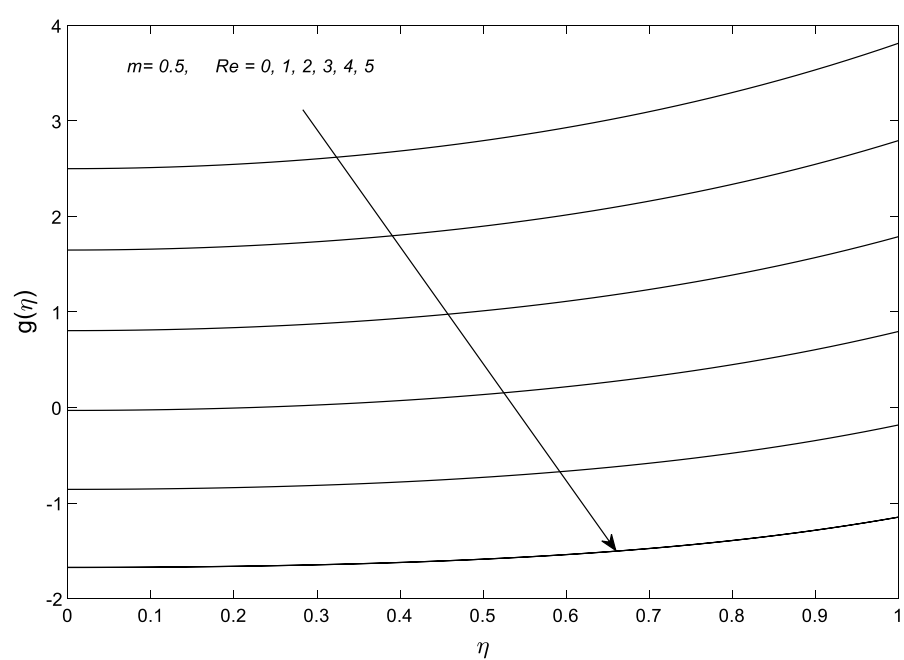

Fig. $4 g$ is graphed against $\eta$ for different $\operatorname{Re}^{*}$ where $\operatorname{Re}^{*}=m \operatorname{Re}$

value. For every value of $\operatorname{Re}^{*}>10: 31$, a reverse flow is observed near the surface of plate. The flow reversal is not occurred for a small value of $\mathrm{Re}^{*}$. It is more interesting that for $m=0, \operatorname{Re}=\operatorname{Re}^{*}=0$, we obtained the classical Hagen-Poiseuille flow profiles and do not present these parabolic velocity profiles in the paper.

The dimensionless pressure is graphed against for $m=0: 5$ and different negative (positive) values of Re in Figs. 3 and 4, respectively. The favorable pressure rises against in both of these two figures, whereas, it is increased nonlinearly against for each Re. In Fig. 3 (Fig. 4) it is decreased with the increasing of Re, however, for large $\operatorname{Re}>0$ (i.e. fast diverging flow) apposing pressure appears at the center of the channel. Note that, for values of Re between two and three, the pressure is apposing at the 


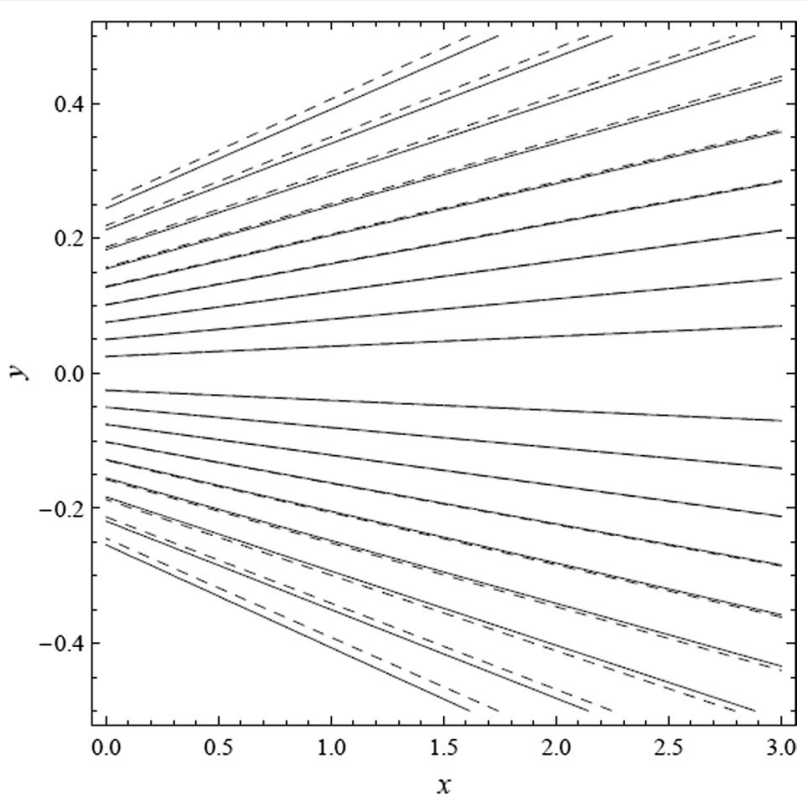

Fig. 5 The stream line $y$ is graphed against the parameters $x$ which show the solid line by $(\operatorname{Re}=-5, m=0: 3)$ and dotted line by $(\operatorname{Re}=5, m=0: 3)$

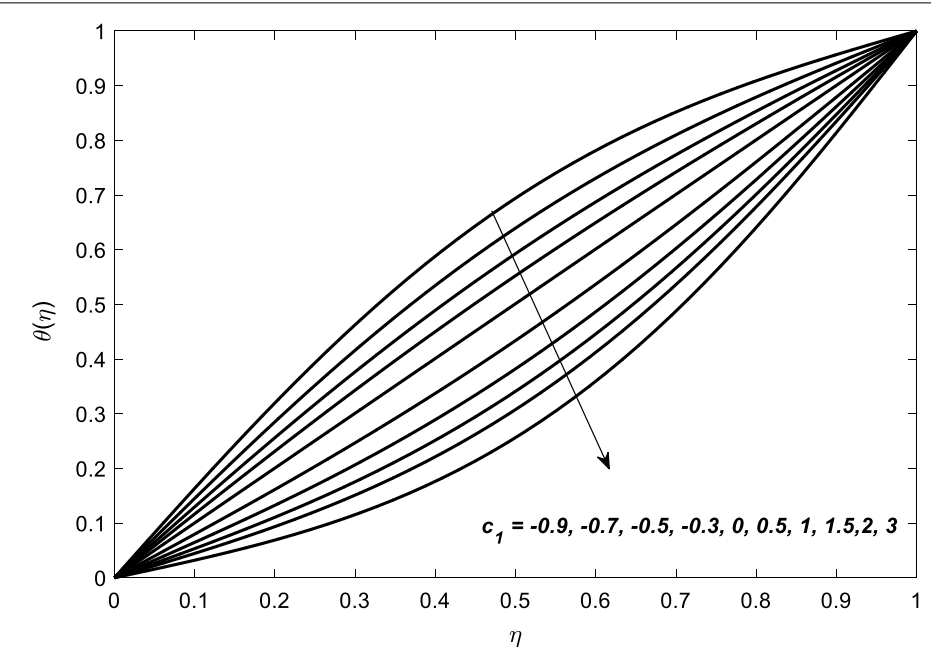

Fig. $6 \theta$ is graphed against $\eta$ for $m=0: 1, \operatorname{Pr}=1$ and $\operatorname{Re} e^{*}=5$

center of the channel, whereas, it is saveable at wall. Furthermore, beyond the values of $\operatorname{Re} \geq 3$, the pressure at center and wall is apposing. For high apposing pressure occurs for $\operatorname{Re}>10$, therefore, the flow separation point appear in such situation.

In Fig. 5, we graphed the streamlines for different values of Re. In this figure, we have shown the perturbation solutions in Eq. (15) for two different values of Re i.e. $\operatorname{Re}=5 ;-5$ and $m=0: 3$. It is observed from this figure that the behavior of streamlines is identical at the center of channel for this set of parameters value, therefore, it is concluded that the Reynolds number ( $\mathrm{Re}$ ) has minor effects on the streamlines near the center of the channel, whereas, slight variation in its profile is observed. 


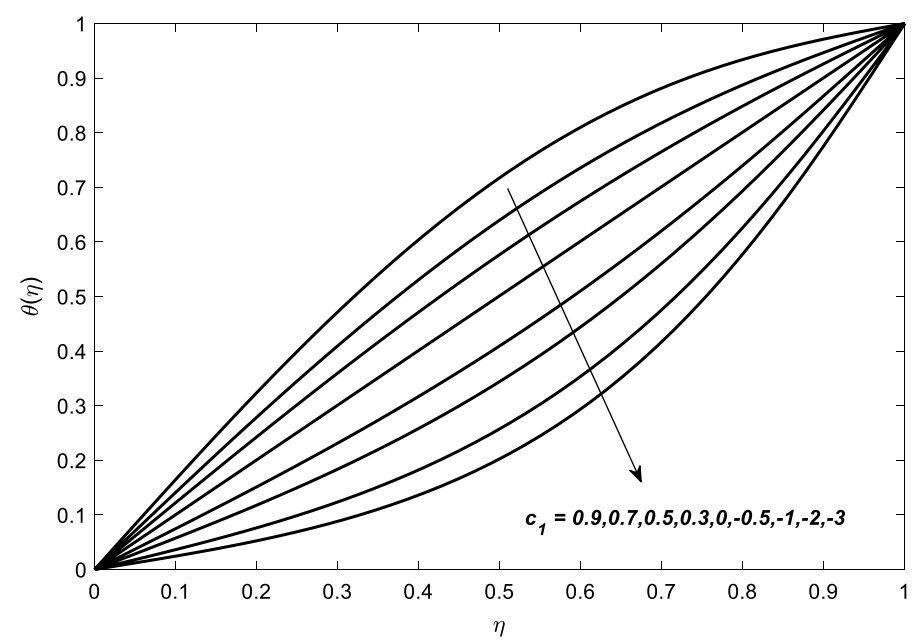

Fig. $7 \theta$ is graphed against $\eta$ for $m=0: 1, \operatorname{Re}^{*}=-5$ and $\operatorname{Pr}=1$

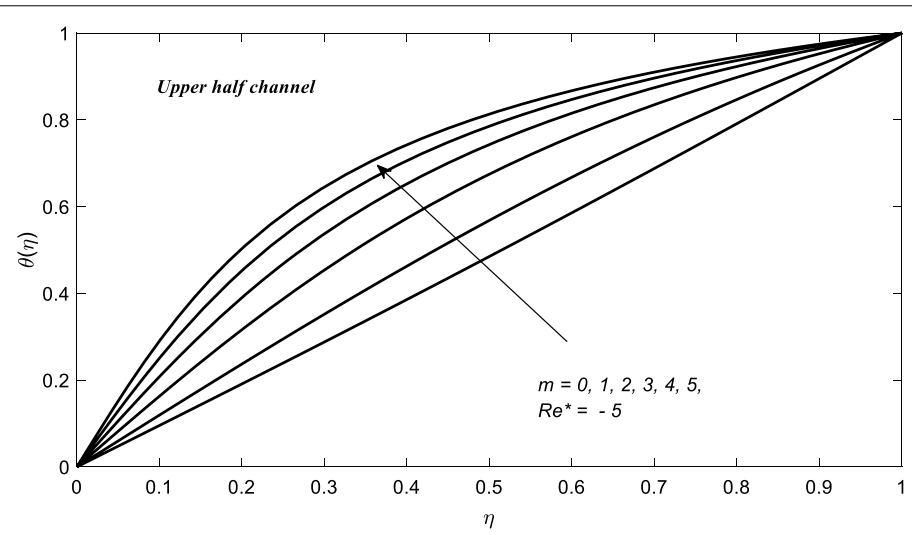

Fig. 8 Converging channel: The dimensionless temperature distribution $(\theta)$ in the upper channel is graphed against $\eta$ for $c_{1}=0.1$ and $\operatorname{Pr}=1$

In Figs. 6 and 7, temperature profiles are graphed against for $\operatorname{Re}^{*}>0\left(\operatorname{Re}^{* *}<0\right)$, different $c_{1}$ (both positive and negative values are taken). In Fig. 6, the temperature profiles are graphed against for diverging flow and different $c_{1}$. The temperature profiles are decreased with increasing $c_{1}<0$ and increased for decreasing $c_{1}>0$. The profiles for $c_{1}<0$ are concave downward whereas for $c_{1}>0$, they are concave upward. The variation in temperature against $c_{1}$ is prominent in case of converging channel flows. It is observed from Fig. 7 that for decreasing values of $c_{1}>0$, the temperature profile are decreased and the profiles are concave downward. The variation in against $c_{1}>0$, is very weak. Similarly for increasing values of $c_{1}<0$, the profiles are increasing and any small changes in $c_{1}$, creates significant changes in the profiles of $\theta$. Note that for $c_{1}=0$, the exact solution of Eq. (13) satisfying the relevant boundary conditions in Eq. (14) is $\theta(\eta)=\frac{\tan ^{-1}(m \eta)}{\tan ^{-1} m}$ and it tends to $\theta_{0}(\eta)=\eta$ (i.e., zeroth order solution for small $m$ in Eq. (18) in the limiting case when $m$ is being approached to zero. 


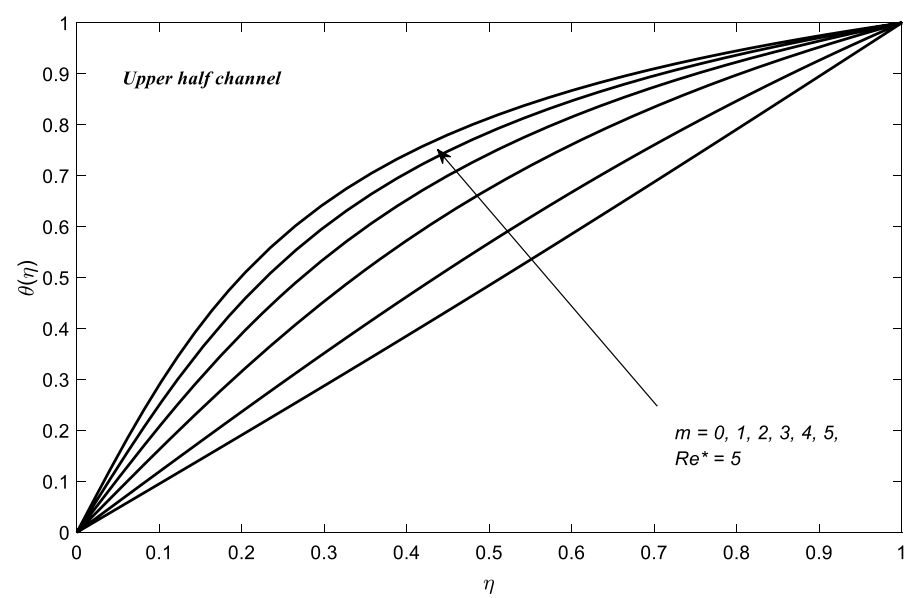

Fig. 9 Diverging channel:The dimensionless temperature distribution $(\theta)$ in upper channel is graphed against $\eta$ for $c_{1}=0.1$ and $\mathrm{Pr}=1$

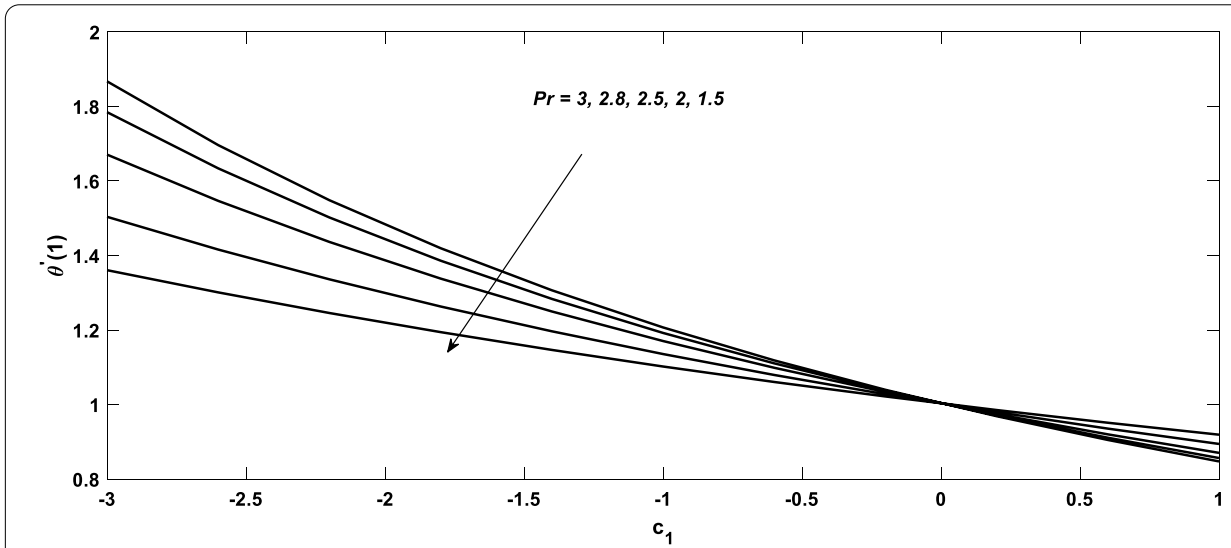

Fig. $10 \theta^{\prime}(1)$ is graphed against $c_{1}$ for $m=0: 1$ and $\operatorname{Re}=5$

The profiles in Figs. 8 and 9 are representing the dimensionless temperature distribution against the similarity variable $(\eta)$ in the upper channel for different values of $m$. Heat transfer in converging and diverging channels is examined in Figs. 8 and 9, respectively. The temperature profiles in either case are increased with increasing of $m$ for converging and diverging channel in the upper channel. For $m=0$, the velocity profiles are linearly changed with while for increasing $m$, the profiles are uniformly increased. The variation in temperature distribution for converging and diverging flows is totally different. The temperature has linear profiles for $m=0$ and exactly same predications are obtained from the zeroth order perturbation solution for $\theta_{0}$ in Eq. (18). The shear stress $(\tau)$ at the flow region is calculated by the formula $\tau=\mu\left(\frac{\partial u}{\partial y}+\frac{\partial v}{\partial x}\right)$. The dimensionless shear stress or the skin friction coefficient $\left(C_{\mathrm{f}}\right)$ at upper sheet is defined by $C_{\mathrm{f}}=\mu\left(\frac{\tau_{h}}{\mu U}\right)$. where $\tau_{h}$ represents shear stress at the upper wall of the channel. By taking the definition of shear stress and substituting the values of velocity components from Eqs. (8)-(9), we get the final candidate for skin friction coefficient at the upper wall as $=f^{\prime}(1)(1-m)$. 


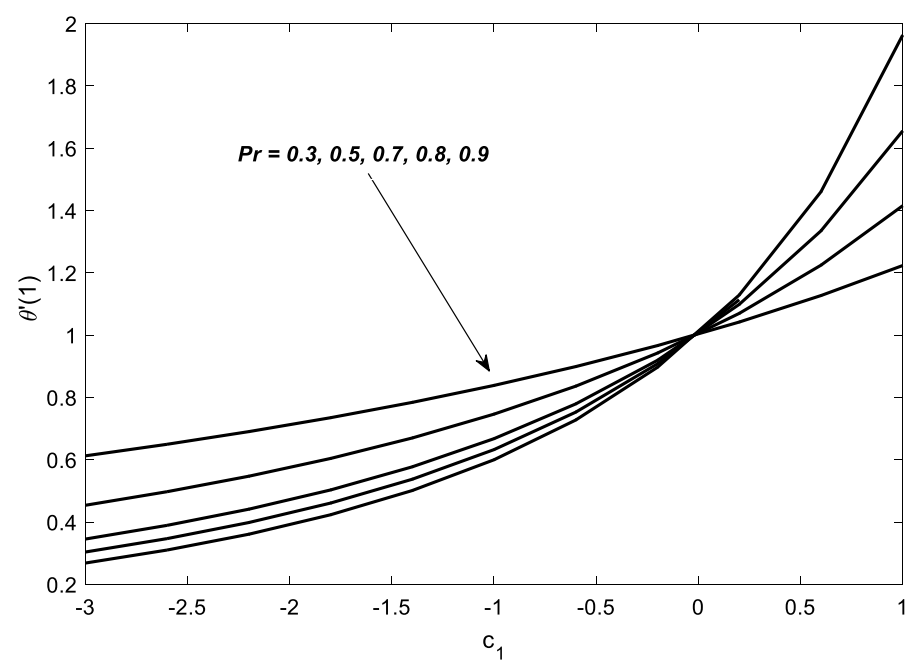

Fig. $11 \theta^{\prime}(1)$ is graphed against $c_{1}$ for $m=0.1$ and $\operatorname{Re}^{*}=-5$

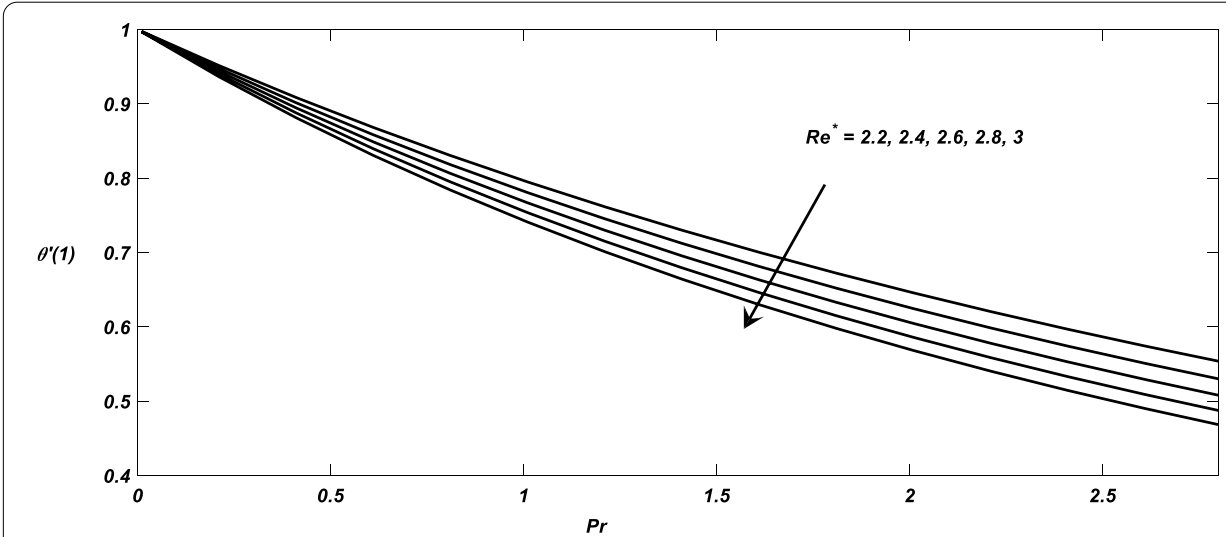

Fig. 12 Upper half of the channel and diverging flow: $\theta^{\prime}(1)$ is graphed against Pr for $m=0: 1$ and $c_{1}=1$

The heat flux $(q)$ at the upper wall of the channel is calculated by the Fourier's law i.e. $q=-k \nabla T=-k\left(\frac{\partial T}{\partial x}, \frac{\partial T}{\partial y}\right)$, where $k$ and $T$ are already defined. In view of the transformation employed in Eq. (9), we get $q_{w}=q_{y=h}=-k \frac{\Delta T}{h(x)}\left(m\left(c_{1}-(1)\right), \theta^{\prime}(1)\right)$, the ratio of $q_{w}$ and $\Delta T$ is known as heat transfer coefficient ( $\left.\varsigma\right)$ and defined by $\varsigma=\frac{q_{w}}{\Delta T}=-\frac{k}{h(x)}\left(m\left(c_{1}-\theta^{\prime}(1)\right), \theta^{\prime}(1)\right)$. Now non-dimensionalized $\varsigma b y \frac{k}{h(x)}$, gives the Nusselt number $\left(N_{u_{h}}\right)$ and written as $\left(N_{u_{h}}\right)=\frac{h(x) \varsigma}{k}=-\left(m\left(c_{1}-\theta^{\prime}(1)\right), \theta^{\prime}(1)\right)$. In either case $\left(N_{u_{h}}\right)$ is directly related to $\theta^{\prime}(1)$.

The amount of thermal energy or heat flux $\theta^{\prime}(1)$ is evaluated and graphed against $c_{1}$ in Fig. 10 for different values of Pr. It is observed from this figure that with the increasing of $\operatorname{Pr}$, the value of $\theta^{\prime}(1)$ increases and the different profiles are intersecting each other at $c_{1}=0$. For $c_{1}=0$, Eq. (13) is reduced to $-2 m 2 \eta \theta^{\prime}-(1+\mathrm{m} 2 \eta 2) \theta^{\prime \prime}=0$, which has an exact solution of the form $\theta(\eta)=\frac{\tan ^{-1}(m \eta)}{\tan ^{-1} m}$. This solution also satisfies the relevant boundary condition in Eq. (14). The amount of heat transfer at the upper plate is evaluated from this exact solution and computed numerically, which has the 


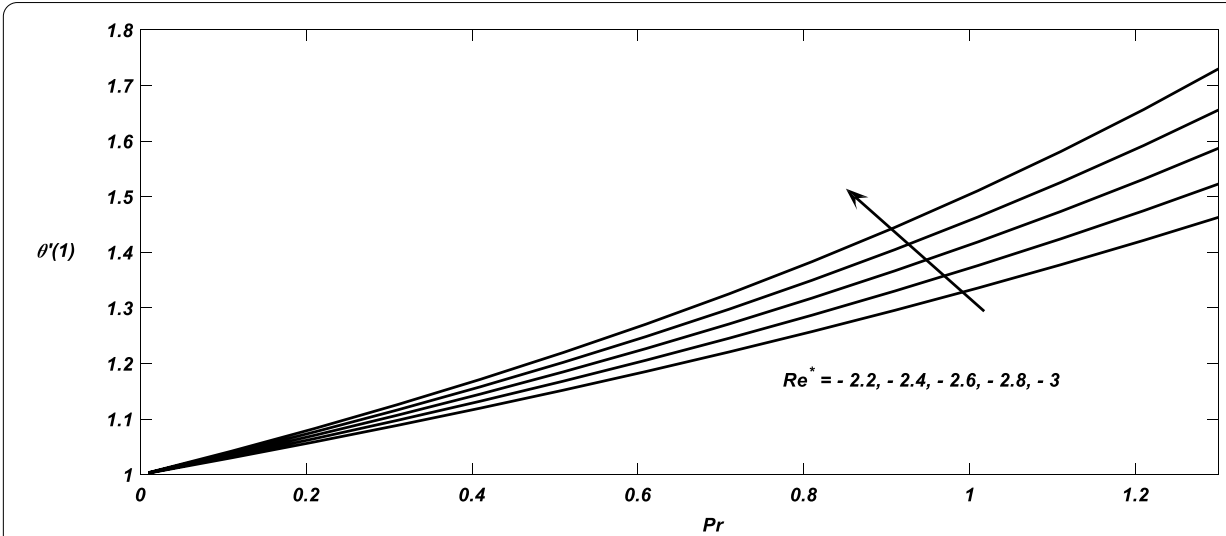

Fig. 13 Upper half of the channel and diverging flow: $\theta^{\prime}(1)$ is graphed against Pr for $m=0: 1$ and $c_{1}=1$

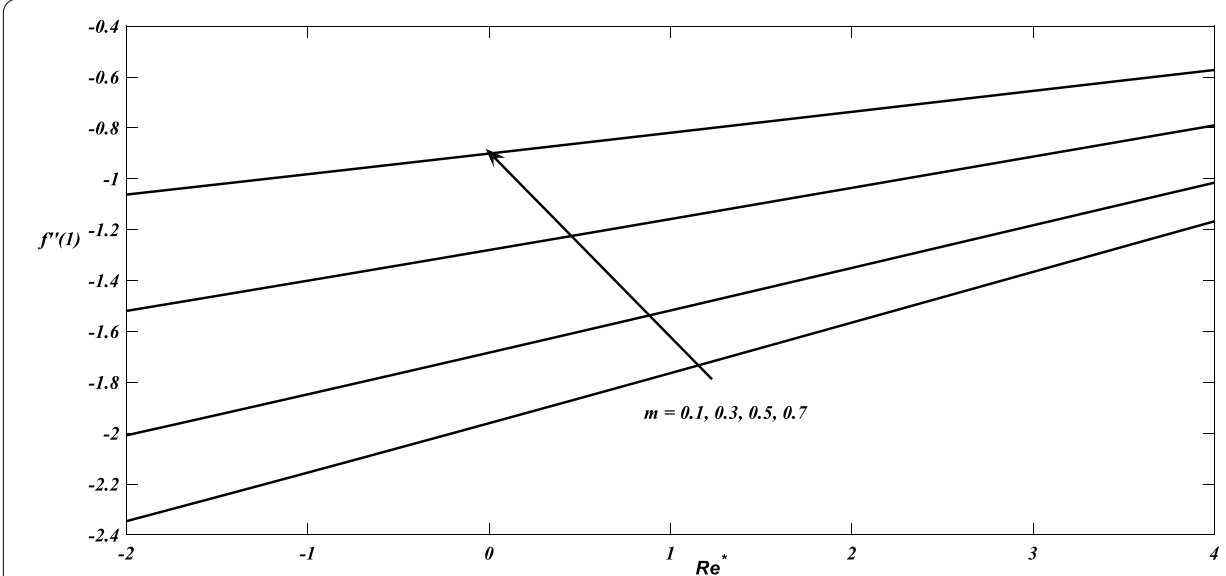

Fig. $14 f^{\prime \prime}(1)$ is graphed against $\operatorname{Re}^{*}$

value 1.00332 . The heat flux at the upper wall is found exactly for $c_{1}=0$ which is $(1)=\frac{m}{\left(1+m^{2}\right) \tan ^{-1} m}$. This value of heat flux at wall can also be conformed from Fig. 10. The heat transfer coefficient is decreased with increasing of $c_{1}$ in case of diverging flow. Heat flux at upper wall is computed and graphed against $c_{1}$ in Fig. 11 for converging flows. It is increased with the increasing of $c_{1}$ and all the profiles are intersecting at ' $(1)=1.00332$ for different Pr. In Fig. 12, '(1) is plotted against Pr for different values of $\operatorname{Re}^{*}$ and for fixed value of $m=0.1$ and $c_{1}=1$ (upper half of the channel and diverging flow). In Fig. 12, it is noticed that the value of $\theta^{\prime}(1)$ is decreased with the increase of $\operatorname{Re}^{*}$ for $\operatorname{Pr}>0$. But reverse phenomenon occurs in Fig. 13 and we observed that the value of '(1) is increased with the decreasing of $\mathrm{Re}^{*}$ for $\operatorname{Pr}$ (upper half of the channel and converging flow). From these two figures i.e. Figures 12 and 13, we observed that, for large positive values of $\operatorname{Re}^{*}$, value of $\operatorname{Pr}>1$, the differences between profiles are more significant. However, for all values of $\operatorname{Re}^{* *}<0$ and the values of $\operatorname{Pr}$ in the interval $0<\operatorname{Pr}<1.4$, the gaps between profiles are more prominent. Moreover, for small values of $\mathrm{Pr}$, the gaps between profiles are negligibly small and these observations are also noted here. For $c_{1}=0, \operatorname{Pr}=0$, Eq. (13) reduced to the form: 


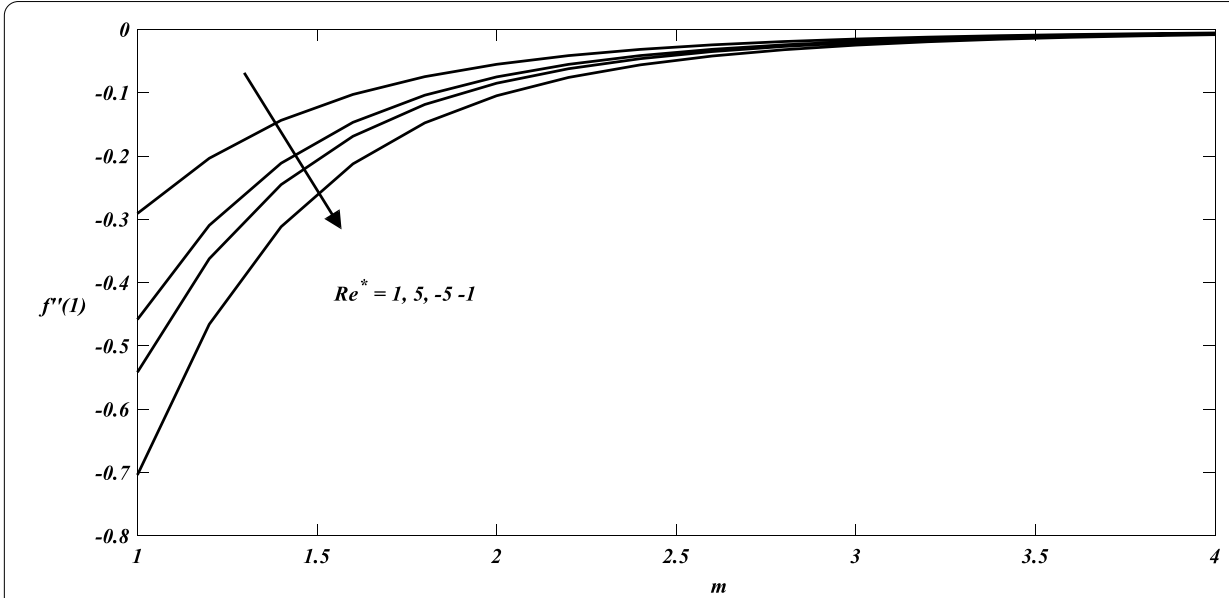

Fig. $15 f^{\prime \prime}(1)$ is graphed against $m$ for different Re*

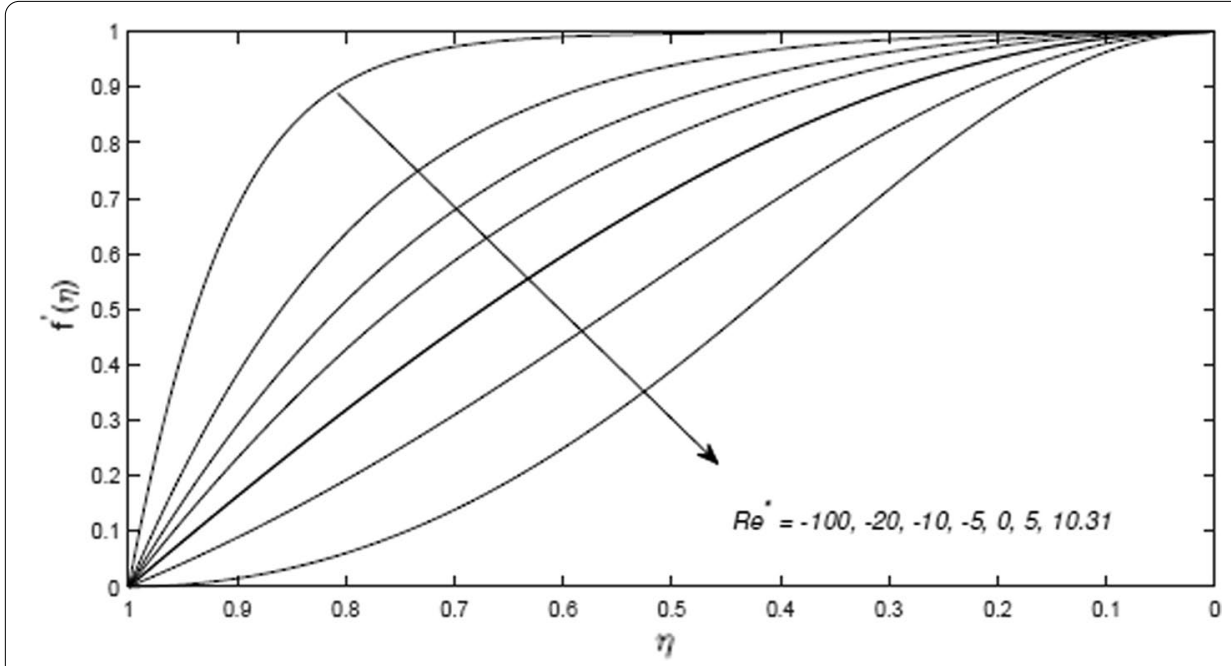

Fig. $16 f^{\prime}$ is plotted against $\eta$ for different values of $\operatorname{Re}^{*}=m \operatorname{Re}$

$-\left(1+m^{2} \eta^{2}\right) \theta^{\prime \prime}=0$. By integrating we obtained $\theta^{\prime}(\eta)=k_{1}$, where $k_{1}$ is any constant of integration. Considering $k_{1}=1$ or used the boundary conditions in Eqs. (14), the amount of heat transfer is $\theta^{\prime}(1)=1$. This claim clearly support the obtained result in figures (Figs. 12 and 13) at $\operatorname{Pr}=0$.

In Fig. 14, the skin friction coefficient is graphed against $\operatorname{Re}^{*}$ for different $m$ and it is also graphed against $m$ in Fig. 15 for different Re* Note that the skin friction coefficient is increased with the increasing of both Re* and $m$. In Fig. 14, it is varied linearly against $\mathrm{Re}^{*}$ for all values of $m$, moreover, the non-linear variation in its behavior is depicted in Fig. 15, whereas, the profiles are started at negative values and vanished at zero asymptotically. Moreover, negative values are representing a dragging force on the fluid and positive sign to correspond opposite behavior. It behaves asymptotically against $m$ for different Re* and reaches zero for large values of $m$. 


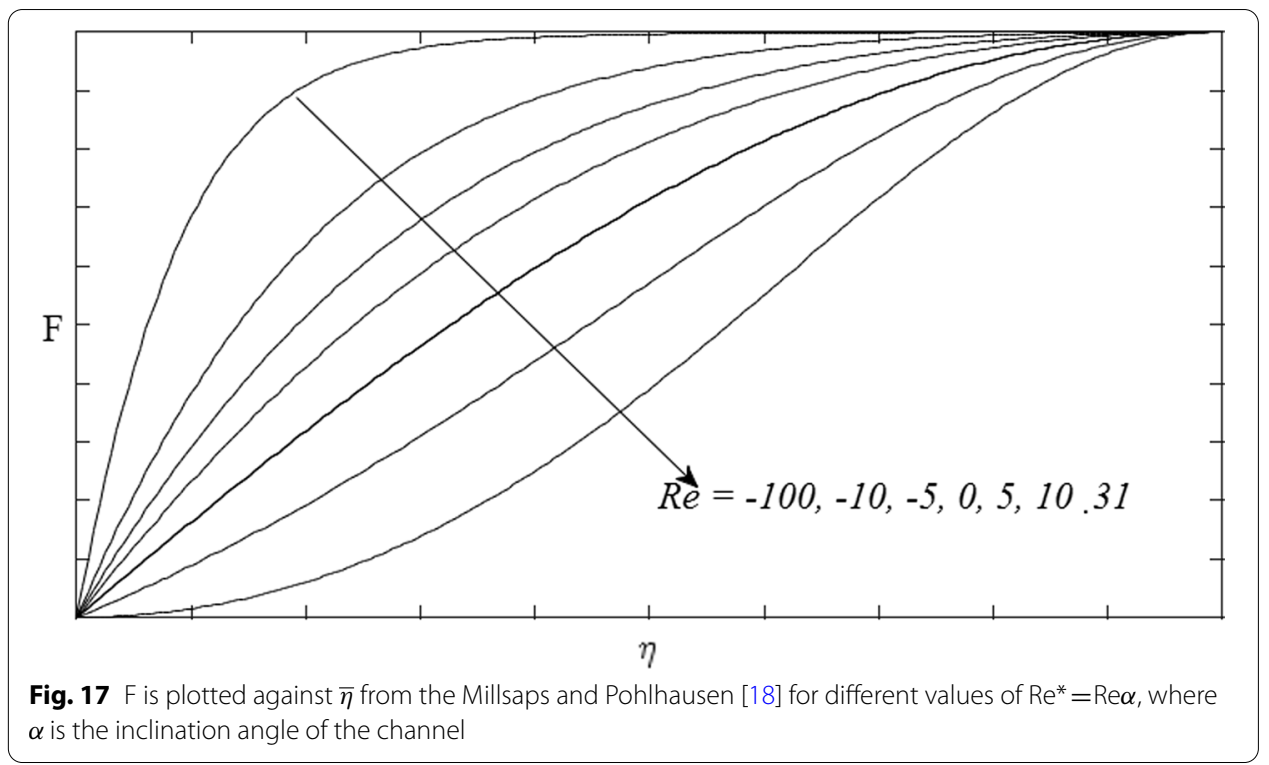

\section{Comparison of present simulations with previously published results}

We compared the present results with the published work of Khan Marwat [29] and Millsaps and Pohlhausen [18] in this section. The numerical solutions of Eq. (12) and relevant boundary conditions in Eq. (14) is graphed in Fig. 16 for $f^{\prime}(\eta)$, different value of $\operatorname{Re}^{*}=m \operatorname{Re}$ and $m=0.1$. These profiles are also reported in Khan Marwat [29]. Moreover, the profiles in Fig. 17 are graphed from the numerical solutions of $F^{\prime \prime}(\bar{\eta})+2 \operatorname{Re} \alpha F(\bar{\eta}) F^{\prime}(\bar{\eta})+4 \alpha^{2} F^{\prime}(\bar{\eta})=0$ with boundary conditions $F(1)=F(-1)=0, F$ $(0)=1$ and this problem is reported in Millsaps and Pohlhausen [18], where, $F(\bar{\eta})$ is representing the radial velocity and $\bar{\eta}=r / \alpha, r$ is the radial coordinate and $\alpha$ is representing the inclination of the channel's wall. Note that the equations in Khan Marwat [29], Millsaps and Pohlhausen [18] are different, but they are presenting the flow inside a converging and diverging channel. The profiles in Figs. 16 and 17 are exactly same and they are obtained from the solution of two different problems.

In Figs. 16 and 17, we compared the present results with the published work and found the same pattern in these two figures.

\section{Conclusion}

The following interesting remarks are solicited from the solutions of the modeled problem where the simulated model describes the flow and heat transfer in a channel of inclined plane walls. The modeled equations are simplified and solved with numerical and analytical means. The two solutions are exactly matched for small value of the parameters of the current modeled problem. The governing equations are simulated for the upper half of the channel and generalized their solutions for the lower half of the channel. However, a solution network is produced for the whole channel. For $m=0$ (i.e. parallel walls channel), we exactly obtained the classical Poiseuille profiles for the velocity and temperature. Later on, a modified Reynolds number is defined by $\operatorname{Re}^{*}=m \operatorname{Re}$ and for different values of $\mathrm{Re}^{*}$ and $m=0$, we obtained the similar profiles as shown in Fig. 2 . Effects of $c_{1}$ (a thermal controlling parameter) are seen on the temperature profiles for both converging and diverging flows. The temperature profiles behaved differently for 
these two different channel models. In case of diverging flow, the temperature profiles are decreased for $-0: 9 \leq c_{1} \leq 2: 3$, whereas, for converging flows, the temperature profiles are increased for $-3 \leq c_{1} \leq 0: 9$. Moreover, the temperature profiles are also graphed in both upper and lower halves of the channel for converging/diverging flows. It is confirmed that the profiles are similar. Besides that skin friction coefficient and heat transfer coefficient at the upper wall of the converging/diverging channel are also calculated and graphed. For zero-value of any of these parameters i.e., either $\operatorname{Pr}=0$, or $m=0$, or $c_{1}=0$, or $\mathrm{Re}^{*}=0$, heat is purely transferred by conduction.

\section{Acknowledgements}

The authors wish to convey their sincere gratitude to the reviewers for their precious comments and suggestions to improve the quality of this manuscript.

\section{Authors' contributions}

$\mathrm{RL}$ carried out the problem design, and code validation. DM carried out the Methodology, reading and correction. AA did the computation, draft preparation and writing. The authors wish to convey their sincere gratitude to the reviewers for their precious comments and suggestions to improve the quality of this manuscript. The authors read and approved the final manuscript.

\section{Funding}

The authors declare that they have no funding.

\section{Availability of data and materials}

All the data generated and material during this study are included in this research article.

Declaration

Competing interests

The authors declare that they have no competing interests.

\section{Author details}

'Department of Mathematics, Faculty of Technology and Engineering Sciences, Islamia College Peshawar, Jamrod Road, University Campus, Peshawar 25120, Khyber Pakhtunkhwa, Pakistan. ${ }^{2}$ Electrical Department, Sarhad University of Science and Information Technology Peshawar, Khyber Pakhtunkhwa, Pakistan.

Received: 4 October 2020 Accepted: 14 July 2021

Published online: 31 July 2021

\section{References}

1. Jasim, H.H., Söylemez, M.S.: Enhancement of natural convection heat transfer of pin fin having perforated with inclination angle. Isi Bilimi ve Teknigi Dergisi/J. Thermal Sci. Technol. 36(2), 111-118 (2016)

2. Jasjeevan, S., Ranjit, S., Brij, B.: Thermo hydraulic performance of solar air duct having triangular protrusions as roughness geometry. J. Thermal Eng. 1:2(Special Issue 7), 607-620 (2015)

3. Tokgöz, N., Aksoy, M.M., Sahin, B.: Experimental investigation of flow characteristics of corrugated channel flow using PIV. J. Thermal Eng. 2(2), 754-760 (2016)

4. Zunaid, M., Jindal, A., Gakhar, D., Sinha, A.: Numerical study of pressure drop and heat transfer in a straight rectangular and semi cylindrical projections microchannel heat sink. J. Thermal Eng. 3(5), 1453-1465 (2017)

5. Mendes, P.S., Sparrow, E.M.: Periodically converging-diverging tubes and their turbulent heat transfer, pressure drop, fluid flow, and enhancement characteristics. J. Heat Transfer 106(1), 55-63 (1984)

6. Garg, V.K., Maji, P.K.: Laminar flow and heat transfer in a periodically converging-diverging channel. Int. J. Numer. Methods Fluids 8(5), 579-597 (1988)

7. Amon, C.H., Mikic, B.B.: Numerical prediction of convective heat transfer in self-sustained oscillatory flows. J. Thermophys. Heat Transfer 4(2), 239-246 (1990)

8. Wang, G.V., Vanka, S.P.: Convective heat transfer in periodic wavy passages. Int. J. Heat Mass Transf. 38(17), 3219-3230 (1995)

9. DeJong, N.C., Jacobi, A.M.: An experimental study of flow and heat transfer in parallel-plate arrays: local, row-by-row and surface average behavior. Int. J. Heat Mass Transf. 40(6), 13651378 (1997)

10. Caliskan, S., Baskaya, S.: Experimental investigation of impinging jet array heat transfer from a surface with $V$-shaped and convergent-divergent ribs. Int. J. Therm. Sci. 59, 234-246 (2012)

11. Kotcioglu, I., Cansiz, A., Khalaji, M.N.: Experimental investigation for optimization of design parameters in a rectangular duct with plate-fins heat exchanger by Taguchi method. Appl. Therm. Eng. 50(1), 604-613 (2013)

12. Erdin, M.T., Yilmaz, T.: Numerical investigation of flow and heat transfer in communicating converging and diverging channels. J. Thermal Eng. 4, 2318-2332 (2018)

13. Gholami, A.A., Wahid, M.A., Mohammed, H.A.: Heat transfer enhancement and pressure drop for fin-and-tube compact heat exchangers with wavy rectangular winglet-type vortex generators. Int. Commun. Heat Mass Transfer $\mathbf{5 4}$ 132-140 (2014) 
14. Min, C., Qi, C., Wang, E., Tian, L., Qin, Y.: Numerical investigation of turbulent flow and heat transfer in a channel with novel longitudinal vortex generators. Int. J. Heat Mass Transf. 55(2324), 7268-7277 (2012)

15. Jeffery, G.B.: L. The two-dimensional steady motion of a viscous fluid. Lond. Edinb. Dublin Philos. Mag. J. Sci. 29(172), 455-465 (1915)

16. Kumar, K.G., Chamkha, A.J.: Darcy-Forchheimer flow and heat transfer of water-based Cu nanoparticles in convergent/divergent channel subjected to particle shape effect. Eur. Phys. J. Plus 134(3), 107 (2019)

17. Karim, S.M., Rosenhead, L.: The second coefficient of viscosity of liquids and gases. Rev. Mod. Phys. 24(2), 108 (1952)

18. Millsaps, K., Pohlhausen, K.:Thermal distributions in Jeffery-Hamel flows between nonparallel plane walls. J. Aeronaut. Sci. 20(3), 187-196 (1953)

19. Fraenkel, L.E.: Laminar flow in symmetrical channels with slightly curved walls II. An asymptotic series for the stream function. Proc. R. Soc. Lond. Ser. A Math. Phys. Sci. 272(1350), 406-428 (1963)

20. Drazin, P.G.: Flow through a diverging channel: instability and bifurcation. Fluid Dyn. Res. 24(6), 321 (1999)

21. Hamadiche, M., Scott, J., Jeandel, D.: Temporal stability of Jeffery-Hamel flow. J. Fluid Mech. 268, 71-88 (1994)

22. Dennis, S.C.R., Banks, W.H.H., Drazin, P.G., Zaturska, M.B.: Flow along a diverging channel. J. Fluid Mech. 336, 183-202 (1997)

23. Malik, M.Y., Salahuddin, T:. Numerical solution of MHD stagnation point flow of Williamson fluid model over a stretching cylinder. Int. J. Nonlinear Sci. Numer. Simul. 16(3-4), 161-164 (2015)

24. Rehman, K.U., Khan, A.A., Malik, M.Y., Zehra, I., Ali, U.: Temperature and concentration stratification effects on nonNewtonian fluid flow past a cylindrical surface. Results Phys. 7, 3659-3667 (2017)

25. Ramesh, K., Devakar, M.: Effect of heat transfer on the peristaltic transport of a MHD second grade fluid through a porous medium in an inclined asymmetric channel. Chin. J. Phys. 55(3), 825-844 (2017)

26. Turkyilmazoglu, M.: Extending the traditional Jeffery-Hamel flow to stretchable convergent/divergent channels. Comput. Fluids 100, 196-203 (2014)

27. Turkyilmazoglu, M.: Exact multiple solutions for the slip flow and heat transfer in a converging channel. J. Heat Transfer 137(10), 101301 (2015)

28. Eckert, E.R.G.: Heat transfer. Ind. Eng. Chem. 46(5), 932-937 (1954)

29. Nawaz, K.M.D., Ali, A., Asghar, S.: Flow between two rectangular inclined plane walls. Chin. J. Phys. 55(4), 1195-1201 (2017)

30. Makinde, O.D., Khan, Z.H., Khan, W.A., Tshehla, M.S.: Magneto-hemodynamics of nano fluid with heat and mass transfer in a slowly varying symmetrical channel. Int. J. Eng. Res. Africa 28, 118-141 (2017)

31. Makinde, O.D., Sibanda, P.: Steady flow in a diverging symmetrical channel: numerical study of bifurcation by analytic continuation. Quaest. Math. 23(1), 45-57 (2000)

\section{Publisher's Note}

Springer Nature remains neutral with regard to jurisdictional claims in published maps and institutional affiliations.

\section{Submit your manuscript to a SpringerOpen ${ }^{\odot}$ journal and benefit from:}

- Convenient online submission

- Rigorous peer review

- Open access: articles freely available online

- High visibility within the field

- Retaining the copyright to your article

Submit your next manuscript at $\boldsymbol{\nabla}$ springeropen.com 